\title{
What are those cilia doing in the neural tube?
}

\author{
Sarah N Bay ${ }^{1,2}$ and Tamara Caspary ${ }^{1 *}$
}

\begin{abstract}
Primary cilia are present on almost all vertebrate cells, and they have diverse functions in distinct tissues. Cilia are important for sensation in multiple capacities in contexts as different as the retina, kidney, and inner ear. In addition to these roles, cilia play a critical part in various developmental processes. Of particular importance is the development of the neural tube, where cilia are essential for the transduction of the Sonic Hedgehog (Shh) signaling pathway that specifies neuronal cell fates. This relationship is well established and is the most recognizable function for cilia in the neural tube, but it may be part of a larger picture. Here, we discuss the links between cilia and Shh signaling, as well as suggesting additional roles for cilia, and mechanisms for their placement, in the neural tube.
\end{abstract}

Keywords: Cilia, neural tube development, PCP signaling, Shh signaling

\section{Review}

Since being functionally linked to the Sonic Hedgehog (Shh) signaling pathway, primary cilia have sparked enormous interest. The initial connection came from an unbiased forward genetic mouse screen in which a number of the mutations disrupted genes important for cilia; the resulting mutant embryos showed abnormal patterning of the neural tube [1,2]. Shh signaling controls neural tube patterning $[3,4]$, and double mutant analysis showed cilia are critical for Shh signal transduction [1,2]. Previously, the focus of most research was on the function of motile cilia, which have a $9+2$ microtubule structure, but the past decade has witnessed an explosion of interest in primary cilia, which lack the inner doublet and instead have a $9+0$ axonemal arrangement. These cilia have now been implicated in many biological processes, from obesity to cancer to learning and memory [5-8]. Indeed, the widespread role of cilia in various systems is made clear by the range of phenotypes present in the ciliopathies, which are human diseases that arise from mutations in cilia genes [9-13]. In this review, we return to the beginning and the source of all the excitement - the embryonic neural tube.

Core progress has been made towards understanding the mechanistic details behind the abnormal neural

\footnotetext{
*Correspondence: tcaspar@emory.edu

'Department of Human Genetics, Emory University School of Medicine, Atlanta, GA 30322, USA

Full list of author information is available at the end of the article
}

patterning of mouse mutants with disrupted cilia $[1,2,14,15]$, but other roles for cilia in the neural tube have yet to be explored. Proper positioning of cilia in several developmental contexts is linked to the planar cell polarity (PCP) pathway, raising the possibility that the placement of cilia in the neural tube may be critical [16-21]. Additionally, specialized ependymal cilia control circulation and mechanosensation of cerebral spinal fluid (CSF) in the ventricles of the brain [22-25], which is derived from the anterior neural tube. Taken together, these data give us a glimpse of what the cilia in the neural tube are really doing there.

\section{Formation of the neural tube}

Following the specification of the germ layers, the neural tube starts to form $[26,27]$. The process proceeds in three dimensions, most critically along the dorsal-ventral (D-V) and anterior-posterior (A-P) body axes. Within the $\mathrm{D}-\mathrm{V}$ axis, the dorsal ectoderm thickens into the neural plate (or neuroepithelium) whose borders then elevate into neural folds and subsequently extend to roll into a tube. The tops of the neural folds fuse along the midline to close the neural tube, and the structure then separates from the overlying surface ectoderm. The floor plate at the ventral midline is induced by Shh from the underlying notochord, and neural patterning proceeds as cell fates are specified along the D-V axis. At the same time, along the A-P axis, the tube narrows and elongates in a process termed convergent extension $(\mathrm{CE})$; errors in 
this step lead to neural tube defects (NTDs), such as craniorachischisis, anencephaly, and spina bifida [28].

\section{Cilia are required for Sonic Hedgehog signaling and neural tube patterning}

Patterning of the neural tube and correct cell fate specification are integral parts of proper development, and tight control of the Shh signaling pathway is required for appropriate ventral patterning and specification of motor neurons and interneurons [29,30]. The dorsal cell fates are specified by the BMP and Wnt signaling pathways. As the links between cilia and Wnt signaling are controversial, they are well reviewed elsewhere [20,31-36]. Clearly, however, cilia are known to be required for Shh signaling in mammals, with many members of the pathway localizing to cilia [37-39].

In the ventral neural tube, a combination of the amount and duration of Shh signaling specifies six neural progenitor cell fates $[29,30,40]$. Due to their proximity to the underlying notochord (the initial source of secreted Shh), the most ventral cells at the midline are exposed to the highest concentrations of Shh and are specified as the floor plate and the p3 domain, which will give rise to V3 interneurons [29,35,41,42]. Intermediate levels of Shh induce the formation of the pMN, $\mathrm{p} 2$, p1, and $\mathrm{p} 0$ domains, precursors to motor neurons and V2, V1, and V0 interneurons, respectively [29,35]. The presence of Shh also inhibits dorsal cell type specification [40]. One of the key features of the Shh gradient that directs patterning is the balance between activator and repressor transcriptional activities. As cells are exposed to varying levels of Shh, a signaling cascade is responsible for the regulation of the Gli family of transcription factors (Gli1 to Gli3), which act as effectors that can activate (GliA) or repress (GliR) transcription of target genes. Gli1 acts solely as an activator, and, though Gli2 and Gli3 both contain repressor domains, Gli2 acts as the primary activator while Gli3 is the major repressor in the neural tube [43-46]. It is ultimately the balance of these two opposing signals that is critical for patterning, and cilia are crucial for maintaining this balance.

The transduction of the signal from Shh ligand to the Gli transcription factors is an intricate cascade involving many elements, including Patched (Ptch1), a transmembrane receptor, Smoothened (Smo), a membrane protein, Suppressor of Fused ( $\mathrm{SuFu}$ ), and Kif7, a possible motor protein. In the absence of Shh, Ptch1 inhibits Smo and causes repression of the pathway [39]. This results in the proteolytic cleavage of Gli3, the major repressor, and the subsequent repression of target genes [46]. When Shh ligand is present, it binds to Ptch1, which removes the repression of Smo [39]. Gli3 is no longer cleaved into the repressor form, Gli2 is stabilized and activated, and the transcription of target genes, among them Ptch1 and Gli1, is promoted.

In vertebrate systems, this signaling cascade happens in the context of the cilium, and the dynamic transport of pathway members is key for proper transduction. When the pathway is off, Ptch1 is localized to the cilium whereas Smo is not; upon stimulation by Shh ligand, Ptch1 leaves the cilium while Smo becomes enriched there [39]. The Gli proteins, Kif7, and SuFu all localize to the tips of cilia [47-50]. Gli proteins are bound and stabilized by $\mathrm{SuFu}$ and bidirectionally trafficked along the axoneme; without pathway activation, they are cleaved to produce GliR $[2,49,50]$. SuFu also acts to inhibit the activation of Gli $[49,50]$. Kif7, the mouse homo$\log$ of Drosophila Costal-2, functions between Smo and the Gli proteins to both negatively and positively regulate the pathway [47]. Though they are not the only regulators, core cilia proteins function prominently in pathway control.

\section{Intraflagellar transport mutants connect cilia transport and Sonic Hedgehog signaling}

Cilia and Shh were initially linked through forward genetics in the mouse, since mutants defective in intraflagellar transport (IFT) proteins showed improper neural tube patterning, and IFT is necessary for ciliogenesis and cilia maintenance $[1,2]$. The IFT particles are composed of two biochemically distinct complexes: IFTA and IFTB [51]. IFTB proteins, along with the molecular motor kinesin-II, are necessary for transport from the base of the cilium to the tip (anterograde transport), and it was mutations in members of this complex that gave the first indication that cilia and Shh signaling were connected. Mutations in IFTB genes, such as Ift88 and Ift172, lead to either absent or severely shortened cilia; this results in no Shh signaling and a lack of both GliA and GliR. Thus, in Ift $88^{\text {pol }}$ and Ift172 ${ }^{\text {wim }}$ mutants, the lack of activation combined with derepression causes neural tube mispatterning $[1,2]$.

Together, IFTA proteins and the cytoplasmic motor dynein power retrograde transport, which traffics proteins from the tip of the cilium back toward the cell [51]. Unlike anterograde transport mutants, which lack cilia, retrograde transport mutants have abnormal cilia morphology due to protein accumulation at the tip of the cilium [48]. This can result in complete blockage of signal transduction (as in Dync2h1, discussed below) or in ectopic pathway activation, as seen in the Ift122 null allele sister of open brain (sob) $[48,52]$. These retrograde defects highlight the fact that the movement of Gli proteins into the cilium is not sufficient to support their proper activity. IFT proteins are not only crucial to build and maintain the cilium, but also to regulate Gli activator and repressor function [48,52]. 
Though originally a topic of intense debate, the claim that transduction of the Shh pathway is intricately tied to proper cilia structure and transport has been supported by the identification of diverse mutants that all disrupt cilia structure or impair cilia protein transport. The simple ability to move pathway components into and out of the cilium is not enough for proper signal transduction; instead, the relative rates of anterograde and retrograde transport are critical. This is demonstrated most strikingly by the genetic interactions of anterograde and retrograde trafficking mutants. Dync2h1 is the heavy chain of dynein, the cytoplasmic motor responsible for retrograde transport, and when it is disrupted (as in its mutant ling-ling), Ptch1, Smo, and Gli2 are all trafficked into the cilium, but no Shh transduction occurs, causing a dorsalized neural tube [52,53]. Interestingly, a single copy of a hypomorphic allele of the anterograde IFTB component, Ift172 (Ift $172^{a v c 1 /+}$ ), rescues the patterning phenotype caused by the absence of retrograde transport [52]. Even more intriguing is the demonstration that reduction of IFT122, an IFTA protein, via Ift $122^{\text {sopb/+ }}$ is also able to suppress the Dync2h1llilln phenotype [52]. Though both Dync2h1 and Ift122 are assumed to be part of the retrograde transport complex, the fact that Ift $122^{\text {sopb/+ }}$ rescues the Dync $2 h 1^{l l n / l l n}$ phenotype suggests that Ift122 may also act outside retrograde transport, emphasizing the nuances of transport necessary for proper signaling. This is further highlighted by recent analysis of an allelic series of IFTA mutants, which demonstrated that proper Shh signaling relies on correct cilia architecture and protein trafficking [54].

In addition to the conserved cilia proteins critical in building and maintaining cilia through multiple phyla, other genes that are important for cilia also regulate Shh signaling. For example, Arl13b and Rab23 are small GTPases, and mutations in either lead to unique defects in neural tube patterning. Strikingly, this is due to loss of Arl13b preventing full activation of GliA but leaving normal GliR function intact [55]. In genetic analysis, Arl13b functions downstream of Smo, but cell biological analysis shows that it also controls entry of Smo into the cilium, arguing that it may possess an additional upstream function [55,56]. Similarly, Rab23 may function to affect cilia trafficking at multiple points. Rab23 mutants display ventralized neural tube patterning, and genetic analysis has placed it downstream of Smo, suggesting that it functions primarily through inhibiting the activation of Gli2 [57-59]. More recently, quantitative analysis of protein trafficking in the cilium has described a role for Rab23 in overseeing the recycling rate of Smo [60]. Furthermore, loss of another Shh inhibitor, TULP3, leads to ventralization of the neural tube [61,62]. TULP3, a tubby-like protein, acts to repress Shh in the absence of ligand in a Gli2-dependent but Smoindependent manner and is vital to balancing progenitor proliferation with neuron differentiation $[61,62]$. Pathway regulators such as these, which act at multiple steps of the cascade, suggest that the cilium as an organelle may function for efficiency; this is to say, its small and controlled environment appears to have evolved to use some proteins in many different capacities as a way to maximize the effectiveness of the system.

\section{Right place ... right time}

Although the intricate connections between cilia and Shh signal transduction are the best understood at present, the cilia within the neural tube may have additional functions. Cilia on cells that line the ventricular zone of the neural tube are aligned and extend into the lumen. This organization is most obvious at the most ventral levels of the ventricular zone near the floor plate. It seems unlikely that this specific orientation is an artifact but rather suggests that the placement of these cilia may be important to their function, to their ability to respond to signal, or to the morphology of the neural tube. For example, it is not yet known whether cilia in the neural tube function solely to transduce the Shh or if they actually sense the Shh ligand. Perhaps this organization of cilia in the ventral neural tube is most obvious as their length there is proportional to their ability to detect Shh ligand. On the other hand, the position of the cilium directly relates to the plane of cell division. As the cells lining the lumen are highly proliferative progenitor cells, a subset of which remain progenitors, the positioning of the cilium could be critical for cellular asymmetry. Shh has a well established role as a mitogen in other tissues [63,64], and the cells in the ventricular zone are highly proliferating progenitors; the cilia could be present for morphogenesis in addition to patterning. Cilia position is critical to proper function in other developmental contexts. For example, PCP, or non-canonical Wnt signaling, controls cilia localization in the embryonic node [19]. Should cilia position in the neural tube be shown to be deliberate, PCP signaling is an excellent candidate for overseeing this process. Additionally, cilia are known for their sensory function in other contexts. In ependymal cells, which line the ventricles of the brain and are responsible for CSF production and circulation, cilia are known to have mechano- and chemosensory roles [23,25]. Thus, it is reasonable to speculate that properly oriented cilia in the neural tube may sense multiple cues.

\section{Planar cell polarity signaling is responsible for cilia orientation}

$\mathrm{CE}$ is critical to neural tube formation as it elongates the tissue so that the brain and spinal cord eventually form. 
Cells that participate in CE must be polarized, and this specific cell shape is dependent on the PCP cascade $[17,28,65,66]$. While this role for PCP in the neural tube is well established, recent research connecting PCP signaling to cilia positioning points to another way this pathway could function in the neural tube. If PCP signaling influences cilia orientation in the neural tube, as it does in other developmental contexts, this would provide a mechanism for the cilia to be in the right place at the right time.

Analyses of mutants in either PCP signaling or ciliogenesis indicate that neither PCP signaling nor CE require cilia. Mutants with disrupted cilia display normal $\mathrm{CE}$, and cilia play no known role in the process. Despite this, a variety of data link PCP signaling and cilia [16-20], raising the possibility that there may be interplay between the two in the neural tube. Mouse models of the human ciliopathy Bardet-Biedl syndrome (BBS) disrupt any of 12 BBS genes, which are localized to the basal body and cilium and have phenotypes reminiscent of PCP mutants [16]. Mutations in either Inturned or Fuzzy, which regulate PCP signaling and CE, also display abnormal ciliogenesis and secondary Shh defects $[17,21]$. Together, these data indicate that PCP signaling and cilia have a relationship. It appears that PCP function is necessary for cilia orientation, which then underlies cilia function. In the embryonic node, PCP signaling positions cilia in order for the flow necessary for left-right axis specification to be established [19]. Furthermore, a core PCP component, Vangl2, genetically interacts with the core cilia machinery protein, IFT88, in kinocilia in the organ of Corti [18]. Together, these data show the reliance of cilia function on proper placement and orientation of the cilium.

Given the role of PCP in cilia orientation, it is vital to determine whether or not PCP signaling influences the position and/or organization of cilia in the ventricular zone of the neural tube. The first step would be to examine cilia in the neural tube of known PCP mutants to determine if the anecdotal arrangement of cilia is disturbed. Finding a way to disrupt the placement of cilia will confirm that their position is indeed deliberate, and from there we will be able to pose the question of mechanism and function.

\section{A sensory role}

What remains unclear is whether the cilia in the neural tube are there solely to transduce Shh signaling. After all, in the lungs, motile cilia that clear mucus also express taste receptors [67], so perhaps all cilia can perform multiple functions. Several systems are suggestive. For instance, the Caenorhabditis elegans nervous system is ciliated, and those cilia are critical for chemosensation [68]. In the mammalian brain, sensory cilia are found on ependymal cells, which are multiciliated epithelial cells that line the ventricles of the brain $[23,25]$. Additionally, these cilia are motile and beat to circulate CSF. Mature ependymal cells develop from radial glial precursors, whose cilia regulate polarization of the mature ependymal cells, underscoring the importance of cilia orientation [22-24]. Furthermore, cells in the choroid plexus possess clusters of primary cilia responsible for CSF production, and loss of these cilia causes defects in autocrine signaling and transcytosis, leading to misregulation of CSF production [25]. These data establish a sensory role for many diverse cilia and make us wonder whether cilia of the neural tube could also have such a function. Additionally, the idea that neural tube cilia may have a sensory function similar to that of the motile cilia discussed raises the question of whether motile cilia could also be playing a role in Shh signaling. Could both sensory and signaling functions be common to multiple types of cilia?

\section{Conclusion}

Since a mouse mutant linked Shh and cilia almost a decade ago, the field has focused on understanding the mechanistic links between the two. This work has painted a dynamic picture, whereby key components move into and out of cilia to regulate the ratio of GliA and GliR and ultimately specify distinct cell fates in the neural tube. Other signaling pathways have also been linked to cilia, although whether such links are critical in the neural tube remains unclear. The projection of cilia into the lumen of the ventricular zone strongly suggests that they could play a sensory role, in which case the positioning of these cilia would be crucial and highly regulated, possibly through PCP signaling. But the biggest question remains: do these cilia play another functional role? Cilia in other contexts are strikingly suggestive, and the field is poised to investigate for what other tasks, if any, the cilia of the neural tube may be responsible.

\section{Abbreviations \\ A-P: anterior-posterior; BBS: Bardet-Biedl syndrome; CE: convergent extension; CSF: cerebral spinal fluid; D-V: dorsal-ventral; IFT: intraflagellar transport; NTD: neural tube defect; PCP: planar cell polarity; Ptch1: Patched; Sh: Sonic Hedgehog; Smo: Smoothened; SuFu: Suppressor of Fused.}

\section{Competing interests}

The authors declare that they have no competing interests.

\section{Authors' contributions}

SNB and TC wrote the manuscript. Neither has any conflict of interest to report. Both authors read and approved the final manuscript.

Acknowledgements

We thank Cheryl Timms Strauss for her comments on the manuscript. 


\section{Author details}

'Department of Human Genetics, Emory University School of Medicine, Atlanta, GA 30322, USA. ${ }^{2}$ Graduate Program in Genetics and Molecular Biology, Atlanta, GA 30322, USA.

\section{Received: 27 April 2012 Accepted: 29 June 2012} Published: 1 October 2012

\section{References}

1. Huangfu D, Liu A, Rakeman AS, Murcia NS, Niswander L, Anderson KV (2003) Hedgehog signalling in the mouse requires intraflagellar transport proteins. Nature 426:83-87

2. Huangfu D, Anderson KV (2005) Cilia and Hedgehog responsiveness in the mouse. Proc Natl Acad Sci U S A 102:11325-11330

3. Tanabe $Y$, Jessell TM (1996) Diversity and pattern in the developing spinal cord. Science 274:1115-1123

4. Echelard Y, Epstein DJ, St-Jacques B, Shen L, Mohler J, McMahon J, McMahon aP (1993) Sonic hedgehog, a member of a family of putative signaling molecules, is implicated in the regulation of CNS polarity. Cell 75:1417-1430

5. Han Y-G, Kim HJ, Aa D, Ellison DW, Gilbertson RJ, Alvarez-Buylla A (2009) Dual and opposing roles of primary cilia in medulloblastoma development. Nat Med 15:1062-1065

6. Wong SY, Seol AD, So P-L, Ermilov AN, Bichakjian CK, Epstein EH, Dlugosz AA, Reiter JF (2009) Primary cilia can both mediate and suppress Hedgehog pathway-dependent tumorigenesis. Nat Med 15:1055-1061

7. Guo D-F, Rahmouni K (2011) Molecular basis of the obesity associated with Bardet-Biedl syndrome. Trends Endocrinol Metab 22:286-293

8. Amador-Arjona A, Elliott J, Miller A, Ginbey A, Pazour GJ, Enikolopov G, Roberts AJ, Terskikh AV (2011) Primary cilia regulate proliferation of amplifying progenitors in adult hippocampus: implications for learning and memory. J Neurosci 31:9933-9944

9. Baker K, Beales PL (2009) Making sense of cilia in disease: the human ciliopathies. Am J Med Genet C Semin Med Genet 151C:281-295

10. Novarino G, Akizu N, Gleeson JG (2011) Modeling human disease in humans: the ciliopathies. Cell 147:70-79

11. Fliegauf $M$, Benzing $T$, Omran $H$ (2007) When cilia go bad: cilia defects and ciliopathies. Nat Rev Mol Cell Biol 8:880-893

12. Singla V, Reiter JF (2006) The primary cilium as the cell's antenna: signaling at a sensory organelle. Science 313:629-633

13. Na D, Li J, Sun Z (2010) Cilia in cell signaling and human disorders. Protein Cell 1:726-736

14. Eggenschwiler JT, Anderson KV (2007) Cilia and developmental signaling Annu Rev Cell Dev Biol 23:345-373

15. Dessaud E, Mcmahon AP, Briscoe J (2008) Pattern formation in the vertebrate neural tube: a sonic hedgehog morphogen-regulated transcriptional network. Development 2503:2489-2503

16. Ross AJ, May-Simera H, Eichers ER, Kai M, Hill J, Jagger DJ, Leitch CC, Chapple JP, Munro PM, Fisher S, Tan PL, Phillips HM, Leroux MR, Henderson DJ, Murdoch JN, Copp AJ, Eliot M-M, Lupski JR, Kemp DT, Dollfus H, Tada M, Katsanis N, Forge A, Beales PL (2005) Disruption of Bardet-Biedl syndrome ciliary proteins perturbs planar cell polarity in vertebrates. Nat Genet 37:1135-1140

17. Park TJ, Haigo SL, Wallingford JB (2006) Ciliogenesis defects in embryos lacking inturned or fuzzy function are associated with failure of planar cell polarity and Hedgehog signaling. Nat Genet 38:303-311

18. Jones C, Roper VC, Foucher I, Qian D, Banizs B, Petit C, Yoder BK, Chen P (2008) Ciliary proteins link basal body polarization to planar cell polarity regulation. Nat Genet 40:69-77

19. Antic D, Stubbs JL, Suyama K, Kintner C, Scott MP, Axelrod JD (2010) Plana cell polarity enables posterior localization of nodal cilia and left-right axis determination during mouse and Xenopus embryogenesis. PLoS One 5: e8999

20. Wallingford JB, Mitchell B (2011) Strange as it may seem: the many links between Wnt signaling, planar cell polarity, and cilia. Genes Dev 25:201-213

21. Heydeck W, Zeng H, Liu A (2009) Planar cell polarity effector gene Fuzzy regulates cilia formation and Hedgehog signal transduction in mouse. Dev Dyn 238:3035-3042

22. Spassky N, Han Y-G, Aguilar A, Strehl L, Besse L, Laclef C, Ros MR, Garcia-Verdugo JM, Alvarez-Buylla A (2008) Primary cilia are required for cerebellar development and Shh-dependent expansion of progenitor pool. Dev Biol 317:246-259

23. Mirzadeh Z, Han Y-G, Soriano-Navarro M, García-Verdugo JM, Alvarez-Buylla A (2010) Cilia organize ependymal planar polarity. J Neurosci 30:2600-2610

24. Kishimoto N, Sawamoto K (2012) Planar polarity of ependymal cilia. Differentiation 83:S86-S90

25. Narita K, Kawate T, Kakinuma N, Takeda S (2010) Multiple primary cilia modulate the fluid transcytosis in choroid plexus epithelium. Traffic 11:287-301

26. Copp AJ, Greene NDE, Murdoch JN (2003) The genetic basis of mammalian neurulation. Nat Rev Genet 4:784-793

27. Greene NDE, Copp AJ (2009) Development of the vertebrate central nervous system: formation of the neural tube. Prenat Diagn 29:303-311

28. Wallingford JB (2006) Planar cell polarity, ciliogenesis and neural tube defects. Hum Mol Genet 15(Suppl 2):R227-R234

29. Briscoe J, Ericson J (1999) The specification of neuronal identity by graded Sonic Hedgehog signalling. Semin Cell Dev Biol 10:353-362

30. Jessell TM (2000) Neuronal specification in the spinal cord: inductive signals and transcriptional codes. Nat Rev Genet 1:20-29

31. Horner VL, Caspary T (2011) Disrupted dorsal neural tube BMP signaling in the cilia mutant Arl13b(hnn) stems from abnormal Shh signaling. Dev Biol 355:43-54

32. Corbit KC, Shyer AE, Dowdle WE, Gaulden J, Singla V, Chen M-H, Chuang P-T, Reiter JF (2008) Kif3a constrains beta-catenin-dependent Wnt signalling through dual ciliary and non-ciliary mechanisms. Nat Cell Biology 10:70-76

33. Ocbina PJR, Tuson M, Anderson KV (2009) Primary cilia are not required for normal canonical Wnt signaling in the mouse embryo. PLoS One 4:e6839

34. Huang P, Schier AF (2009) Dampened Hedgehog signaling but normal Wnt signaling in zebrafish without cilia. Development 136:3089-3098

35. Briscoe J, Ericson J (2001) Specification of neuronal fates in the ventral neural tube. Curr Opin Neurobiol 11:43-49

36. Ma L, Schroth J, Gleeson JG (2011) Subcellular spatial regulation of canonical Wnt signalling at the primary cilium. Nat Cell Biol 13:700-707

37. Haycraft CJ, Banizs B, Aydin-Son Y, Zhang Q, Michaud EJ, Yoder BK (2005) Gli2 and Gli3 localize to cilia and require the intraflagellar transport protein polaris for processing and function. PLoS genetics 1:e53

38. Corbit KC, Aanstad P, Singla V, Norman AR, Stainier DYR, Reiter JF (2005) Vertebrate Smoothened functions at the primary cilium. Nature 437:1018-1021

39. Rohatgi R, Milenkovic L, Scott MP (2007) Patched1 regulates hedgehog signaling at the primary cilium. Science 317:372-376

40. Ericson J, Rashbass P, Schedl A, Brenner-Morton S, Kawakami A, van Heyningen V, Jessell TM, Briscoe J (1997) Pax6 controls progenitor cell identity and neuronal fate in response to graded Shh signaling. Cell 90:169-180

41. Roelink H, Porter JA, Chiang C, Tanabe Y, Chang DT, Beachy PA, Jessell TM (1995) Floor plate and motor neuron induction by different concentrations of the amino-terminal cleavage product of sonic hedgehog autoproteolysis. Cell 81:445-455

42. Chamberlain CE, Jeong J, Guo C, Allen BL, McMahon AP (2008) Notochord derived Shh concentrates in close association with the apically positioned basal body in neural target cells and forms a dynamic gradient during neural patterning. Development 135:1097-1106

43. Persson M, Stamataki $D$, te Welscher $P$, Andersson $E$, Böse J, Rüther $U$, Ericson J, Briscoe J (2002) Dorsal-ventral patterning of the spinal cord requires Gli3 transcriptional repressor activity. Genes Dev 16:2865-2878

44. Ding Q, Motoyama J, Gasca S, Mo R, Sasaki H, Rossant J, Hui CC (1998) Diminished Sonic hedgehog signaling and lack of floor plate differentiation in Gli2 mutant mice. Development 125:2533-2543

45. Matise MP, Epstein DJ, Park HL, Platt KA, Joyner AL (1998) Gli2 is required for induction of floor plate and adjacent cells, but not most ventral neurons in the mouse central nervous system. Development 125:2759-2770

46. Litingtung Y, Chiang C (2000) Specification of ventral neuron types is mediated by an antagonistic interaction between Shh and Gli3. Nat Neurosci 3:979-985

47. Liem KF, He M, Ocbina PJR, Anderson KV (2009) Mouse Kif7/Costal2 is a cilia-associated protein that regulates Sonic hedgehog signaling. Proc Natl Acad Sci U S A 106:13377-13382

48. Qin J, Lin Y, Norman RX, Ko HW, Eggenschwiler JT (2011) Intraflagellar transport protein 122 antagonizes Sonic Hedgehog signaling and controls 
ciliary localization of pathway components. Proc Natl Acad Sci U S A 108:1456-1461

49. Wang C, Pan Y, Wang B (2010) Suppressor of fused and Spop regulate the stability, processing and function of Gli2 and Gli3 full-length activators but not their repressors. Development 137:2001-2009

50. Chen M-H, Wilson CW, Li Y-J, Law KKL, Lu C-S, Gacayan R, Zhang X, C-chung H, Chuang P-T (2009) Cilium-independent regulation of Gli protein function by Sufu in Hedgehog signaling is evolutionarily conserved. Genes Dev 23:1910-1928

51. Rosenbaum JL, Witman GB (2002) Intraflagellar transport. Nat Rev Mol Cell Biol 3:813-825

52. Ocbina PJR, Eggenschwiler JT, Moskowitz I, Anderson KV (2011) Complex interactions between genes controlling trafficking in primary cilia. Nat Genet 43:547-553

53. García-García MJ, Eggenschwiler JT, Caspary T, Alcorn HL, Wyler MR Huangfu D, Rakeman AS, Lee JD, Feinberg EH, Timmer JR, Anderson KV (2005) Analysis of mouse embryonic patterning and morphogenesis by forward genetics. Proc Natl Acad Sci U S A 102:5913-5919

54. Liem KF, Ashe A, He M, Satir P, Moran J, Beier D, Wicking C, Anderson KV (2012) The IFT-A complex regulates Shh signaling through cilia structure and membrane protein trafficking. J Cell Biol 197:789-800

55. Caspary T, Larkins CE, Anderson KV (2007) The graded response to Sonic Hedgehog depends on cilia architecture. Dev Cell 12:767-778

56. Larkins CE, Aviles GDG, East MP, Ra K, Caspary T (2011) Arl13b regulates ciliogenesis and the dynamic localization of Shh signaling proteins. Mol Biol Cell 22:4694-4703

57. Eggenschwiler JT, Espinoza E, Anderson KV (2001) Rab23 is an essential negative regulator of the mouse Sonic hedgehog signalling pathway. Nature 412:194-198

58. Eggenschwiler JT, Bulgakov OV, Qin J, Li T, Anderson KV (2006) Mouse Rab23 regulates hedgehog signaling from smoothened to Gli proteins. Dev Biol 290:1-12

59. Wang Y, Ng EL, Tang BL (2006) Rab23: what exactly does it traffic? Traffic 7:746-750

60. Boehlke C, Bashkurov M, Buescher A, Krick T, John A-K, Nitschke R, Walz G, Kuehn EW (2010) Differential role of Rab proteins in ciliary trafficking: Rab23 regulates smoothened levels. J Cell Sci 123:1460-1467

61. Norman RX, Ko HW, Huang V, Eun CM, Abler LL, Zhang Z, Sun X, Eggenschwiler JT (2009) Tubby-like protein 3 (TULP3) regulates patterning in the mouse embryo through inhibition of Hedgehog signaling. Hum Mol Genet 18:1740-1754

62. Patterson VL, Damrau C, Paudyal A, Reeve B, Grimes DT, Stewart ME, Williams DJ, Siggers P, Greenfield A, Murdoch JN (2009) Mouse hitchhiker mutants have spina bifida, dorso-ventral patterning defects and polydactyly: identification of Tulp3 as a novel negative regulator of the Sonic hedgehog pathway. Hum Mol Genet 18:1719-1739

63. Va W (1999) Purkinje-cell-derived Sonic hedgehog regulates granule neuron precursor cell proliferation in the developing mouse cerebellum. Curr Biol 9:445-448

64. Fuccillo M, Joyner AL, Fishell G (2006) Morphogen to mitogen: the multiple roles of hedgehog signalling in vertebrate neural development. Nat Rev Neurosci 7:772-783

65. Wallingford JB, Fraser SE, Harland RM (2002) Convergent extension: the molecular control of polarized cell movement during embryonic development. Dev Cell 2:695-706

66. Heisenberg CP, Tada M, Rauch GJ, Saúde L, Concha ML, Geisler R, Stemple DL, Smith JC, Wilson SW (2000) Silberblick/Wnt11 mediates convergent extension movements during zebrafish gastrulation. Nature 405:76-81

67. Shah AS, Ben-Shahar Y, Moninger TO, Kline JN, Welsh MJ (2009) Motile cilia of human airway epithelia are chemosensory. Science 325:1131-1134

68. Bae Y-K, Barr MM (2008) Sensory roles of neuronal cilia: cilia development, morphogenesis, and function in C. elegans. Front Biosci 13:5959-5974

doi:10.1186/2046-2530-1-19

Cite this article as: Bay and Caspary: What are those cilia doing in the neural tube? Cilia 2012 1:19.

\section{Submit your next manuscript to BioMed Central and take full advantage of:}

- Convenient online submission

- Thorough peer review

- No space constraints or color figure charges

- Immediate publication on acceptance

- Inclusion in PubMed, CAS, Scopus and Google Scholar

- Research which is freely available for redistribution

Submit your manuscript at www.biomedcentral.com/submit 